\title{
The Demand for Gold by Industry
}

\author{
THE EUROPEAN AND AMERICAN MARKETS
}

\author{
Timothy D. Cooke
}

International Gold Corporation Limited, Johannesburg, South Africa

\begin{abstract}
Little information on the consumption of gold in technological or decorative applications is published. The International Gold Corporation therefore recently commissioned detailed surveys in Western Europe and the U.S.A. with the objective of acquiring quantitative data on two markets which together account for a major fraction of the total demand for gold for fabrication. The present article relies heavily on the results of these studies which were conducted by Michalopoulos and Parker, of Washington, D.C., C.G. Wedgewood and Co., of London, and Battelle Research Centre, of Geneva.
\end{abstract}

The total supply of gold for fabrication is made up of newly mined and recycled gold. Of the 521 tons of newly mined gold used for fabrication in the Western World during 1980 (Table I), some 207 tons was used for industrial purposes (1). This 40 per cent share of the total was used for dentistry, electronics, and decorative and other industrial applications.

The purpose of this article is to discuss the demand for gold in electronics, and decorative and other industrial applications in two major markets, the U.S.A. and Western Europe. Information has been drawn from data contained in recent studies (2 to 5 ) commissioned by the International Gold Corporation in these two areas which, together, account for nearly three quarters of the total usage of gold for these applications in the Western World.

Very little detailed information has hitherto been available on the consumption of gold in electronic and decorative applications. Some

Table I

Consumption of Newly Mined Gold in Different Applications in 1980. After (1)

\begin{tabular}{l|c}
\hline Application & $\begin{array}{c}\text { Consumption, } \\
\text { Carat jewellery }\end{array}$ \\
\hline Official coins & 120 \\
Medals, medallions, fake coins & 179 \\
Sub-total & 15 \\
Industrial & 314 \\
Electronics & \\
Other industrial/decorative & 81 \\
Dentistry & 64 \\
Sub-total (industrial) & 62 \\
Total & 207 \\
\end{tabular}

-A further 235 tons of recycled gold is estimated by the author to have been used to manufacture carat jewellery in 1980 estimates have been included in the regular reports by Consolidated Gold Fields, and statistics collected by government agencies have been published in theU.S.A., but these have not been readily comparable, because of the use of different and incompatible methods of defining product categories.

\section{Market Surveys}

The purpose of conducting the present studies was three-fold:

(1) To estimate the total market for gold in the electronic, engineering and decorative sectors

(2) To identify and quantify the principal applications within each sector

(3) To identify the trends which have marked the consumption of gold in each sector, and to forecast those which are likely to prevail in the future.

The research consultants held discussions with the major manufacturers and gold processors in each market area. In the U.S.A., 30 manufacturers of electronic or electrical equipment, and 33 of decorative products were contacted; in Western Europe the corresponding figures were 29 and 27 , repectively. During early 1981 , a programme of desk research was conducted. In the first stage of this, technical literature was analyzed and the principal suppliers of gold were identified. The forms in which gold was required were also listed and current technological innovations and changesstudied. Interviews were then conducted with senior representatives of the major gold users. Where such personal contact was not possible, contact was established by telephone, letter or telex.

In order to avoid duplication of consumption data, firms were asked for their estimates of national consumption rather than for details of their own usage of gold. This procedure also circumvented the problems which might have arisen concerning confidentiality of data. Where official statistics were available, these provided a double check on the estimates given.

The levels of gold consumption recorded below are not claimed to be the precise quantities used within the different market segments. They are based, however, upon estimates made by leading and well informed processors and users of gold. 


\section{Electronics}

Approximately 33 tons of gold was used in electronics applications in the U.S.A. during 1980 (2), and slightly less, 25 tons, in Western Europe (4). Table II shows how this was distributed between various products, of which connectors and printed circuits together accounted for nearly 60 per cent of the gold, with semiconductors consuming 17 per cent.

Some 40 per cent of the gold wasconsumed in connectors, primarily as electrodeposits on the surfaces of pins and sockets. Gold is specified or this application because of its excellent electrical conductivity and wear resistance (as electrodeposit), and its exceptional resistance to corrosion. Grold is particularly desirable where connectors are used at low voltages, for example in computers and other electronic equipment. Where high reliability is required, in defence and aetospace applications especially, gold is used extensively and, in fact, has no significant competitor at present.

Since the first sharp rise in the price of gold, in 1973 and 1974 , methods of economizing on the amount of gold used in connectors have been implemented by the electronics and electrical industries. These methods include:

(1) Selective plating

(2) Taper plating

(3) Spot and stripe plating

(4) Gold inlaying

(5) Gold dot welding

(6) Use of thinner coatings

(7) Use of lower carat gold for all or part of coatings

(8) Use of altemative materials.

These developments took place primarily at the lower quality end of the market. There is, however, a limit to the extent to which further economies are possible. Plating thicknesses cannot be reduced to the point at which the wear and corrosion resistances of components are adversely affected.

The size of components has been reduced over the years. A striking example is that of a standard type of cylindrical connector which accommodated 24 contacts in 1940,61 in 1960 and 128 in 1980. Its mass was progressively reduced from 210 to $85 \mathrm{~g}$ during this period (6).

Concurrent with miniaturization and the trend towards the use of less gold per component, has been the remarkable increase in the output of the electronics industry through natural growth, which has tended to balance the decline in the use of gold arising from the former developments.

According to Electronic News (6), the annual growth rate of the American connector market has slowed down to 10 per cent in 1981 compared with the 20 per cent previously recorded. This is thought to be largely due to the effects of a soft economy and high interest rates which affect most of the capital-intensive telecommunication and large computer companies. While demand for all types of connectors reflected the economic slowdown, that for flat cable connectors was the least affected, with an increasing number of applications such as personal computers and others, previously using card edge connectors, becoming apparent. The use of the co-axial connector also showed steadier growth than those of most other types, due to its unique application in military electronics and other secure communication systems. Due to the slowdown in aircraft construction, rack and panel connectors showed the least growth. The distribution of connector types in the U.S.A. market is shown in Table III.

Minimal substitution of gold has taken place in the government and aetospace sectors, because of the emphasis placed in these areas on the reliability of components. However, there has been a degree of stagnation in government procurement of electronic goods in the last few years, and this has had an adverse effect on the amount of gold used.

Another important application of gold in electrical and electronic engineering is in printed circuits. Gold currently represents between 1 and 10 per cent of the cost of a typical circuit board (2). It is used in plating the contact points which mate with the edge connectors and in

Table II

Gold Usage in the Electronic and Electrical Industry in 1980. After $(2,4)$

\begin{tabular}{l|r|r|r|r}
\hline \multicolumn{1}{c|}{ Application } & \multicolumn{4}{|c}{ Consumption } \\
& $\mathrm{t}$ & $\%$ & $\mathrm{t}$ & U.S.A., \\
\hline Connectors/contacts & 10.2 & 41 & 13.4 & 38 \\
Printed circuits & 5.4 & 22 & 5.2 & 15 \\
Semiconductors & 3.4 & 14 & 6.9 & 19 \\
Electron tubes & $\mathrm{n} . \mathrm{a}$ & $\mathrm{n} . \mathrm{a}$. & 1.1 & 3 \\
Relays and switches & 3.2 & 13 & 1.7 & 5 \\
Thin film metallization & 0.7 & 2 & 2.4 & 7 \\
Thick films & 0.5 & 2 & 2.6 & 7 \\
Other & 1.6 & 6 & 2.0 & 6 \\
Total & 25.6 & 100 & 35.3 & 100
\end{tabular}

Table III

Market Share of Connector Types in the U.S.A. during 1981. After (6)

\begin{tabular}{l|c}
\hline Connector type & Share \% \\
\hline Printing wiring & 24 \\
Cylindrical & 23 \\
Rack and panel & 17 \\
Co-axial & 8 \\
Flat cable & 7 \\
Other & 21 \\
Total & 100
\end{tabular}


the integrated sockets. In the past, gold was used to protect the complete printed wiring. However, because in modem practice only the contact areas are gold-plated, approximately only $1 \mathrm{~g}$ of gold is used on average for each square metre of circuit board. Growth in the computer and telecommunications industries, and also in new applications such as in automobiles and domestic appliances, however, is likely to sustain gold usage in this area. In Europe, for example, the market value for printed circuit boards has been forecast as increasing from U.S. $\$ 1169$ million in 1979 to U.S. $\$ 1417$ million in 1981 (4).

In thick film technology, circuits are made from pastes containing gold or gold alloy powders. Substitution of gold has adversely affected its use except in the French telecommunication industry.

In contrast to those areas in which industry is seeking to minimize the use of gold, there are a number of technological developments which have exploited the properties of gold for new applications. Thin film metallizations are one such development, and are considered by the parties interviewed to have accounted for the largest percentage increase in any electronic application of gold over the last 10 years.

\section{Future Prospects}

Efforts aimed at technological substitution and more efficient use of gold will continue in the electronics and electrical industry. The competitive nature of individual organizations will induce them to seek areas for cost cutting and, inevitably, gold will be one of these. The mass of gold per connector will further decrease towards a lower limit defined by reliability and practical criteria, as the efficiency of selective application of gold in small areas rises (probably towards a practical maximum) with the introduction of new equipment and techniques.

Table N

Breakdown of the Gold.Using Decorative Markets in Western Europe and the U.S.A. After $(3,5)$

\begin{tabular}{|c|c|c|c|c|}
\hline \multirow[t]{2}{*}{ Market } & \multicolumn{2}{|c|}{ W. Europe, } & \multicolumn{2}{|c|}{ U.S.A., } \\
\hline & $t$ & $\%$ & $t$ & $\%$ \\
\hline $\begin{array}{l}\text { Gold filled and plated } \\
\text { jewellery and }\end{array}$ & & & & \\
\hline watches & 6.3 & 45.3 & 14.0 & 71.8 \\
\hline $\begin{array}{l}\text { Writing instruments } \\
\text { and lighters }\end{array}$ & 1.9 & 13.6 & $20^{*}$ & 103 \\
\hline Spectacle frames & 1.8 & 12.9 & 0.5 & 2,5 \\
\hline $\begin{array}{l}\text { Liquid gold/gold leaf } \\
\text { (china, glassware, } \\
\text { bookbinding) }\end{array}$ & 1.4 & 10.1 & 1.5 & 7.7 \\
\hline Others & 2.5 & 18.0 & $1.5^{\star}$ & 7.7 \\
\hline Total & 13.9 & 100.0 & 19.5 & 100.0 \\
\hline
\end{tabular}

"In the U.S.A. data, the consumption figure for 'lighters' has been included in the 1.5 tons of 'other' use.
On the other hand, the output of the electrical and electronics industries will continue to expand through natural growth, and a concomitant increase in the output of gold-containing components will tend to counteract the expected reduction in the amount of gold used per component. The growth of the industrial and electronic sectors is expected to be faster, according to some observers, in the 1980 's than in the previous decade (2).

In particular, defence spending is likely to expand considerably in the U.S.A. (2), leading to an expansion of that element of the electronics industry which is the heaviest user of gold per unit of output, because of the need within the military for maximum reliability. Furthermore, new uses for gold could occur as a result of technological innovations yet to reach the market place.

The conclusion, therefore, is that any significant change in the amount of gold used in this field in the foreseeable future will depend upon the performances of the electronics industries in Europe and the U.S.A., which in turn are largely dependent on the economic situations in these two areas.

\section{Other Technical Applications}

The unique properties of gold are finding applications in many diverse modern technological fields. These tange from the protection of communication satellite antennae with gold coatings to the use of gold alloy brazes to join alloy components in jet and rocket engines. Other applications include thin gold films which act as heating elements in the windshields of aircraft to prevent icing or misting. Thinner films of gold on glass windows have the property of retaining heat in cold climates and reflecting external heat in warmer conditions. These and other engineering uses accounted for nearly 18 tons of gold in Western Europe and the U.S.A. in 1980.

\section{Decorative Uses of Gold}

The term 'decorative uses' refers to applications of gold in the field of costume (non-carat) jewellery, watches and straps, writing instruments, spectacle frames, cosmetics containers, china and glassware, and others such as tableware, fixtures and lighters.

In 1980, the decorative markets in Western Europe and the U.S.A. absorbed a total of about 34 tons of gold, and this is broken down as shown in Table IV. The figure which is given in (1) for the consumption of gold in applications of plated gold (excluding electronics usage), liquid gold used in ceramics, rolled gold, industrial and laboratory chemicals in Western Europe and the U.S.A. is 45.1 tons. However, this total includes a number of applications which are not considered to be decorative within the context of this article.

The use of gold coatings in costume jewellery and watches is by far the largest application of the metal in the decorative segment, accounting for 62 per cent of the total amount of gold consumed in that market. Electroplated gold is much more popular in Europefor this application than in the U.S.A., although in both regions it's use is increasing compared to rolled gold. In Europe, in 1980, about 5.5 tons of 
plated gold are estimated to have been used in the costume jewellery and watch industries compared to 0.8 tons of tolled gold ( 5 ). In the U.S.A., these industries used 10 tons of gold filled (rolled gold), and 4 tons of gold plate in the same period (3). Differences between the regions in the way the statistics are compiled make it impossible to discuss them in greater detail. The decrease, shown in Table V, found in the use of rolled gold in the U.S. costume jewellery and watch industries probably reflects the public's growing preference for more intricate designs not readily achieved with gold filled materials.

Although the price of gold has steadily increased in tecent years there has been no discernibleshift in consumer preference from carat to gold-filled jewellery. This latter segment appears to be 'squeezed' between carat jewellery, which consumers still prefer even though they may have to buy it more circumspectly, and the much less expensive plated products which often have a down-market image.

A number of watch manufacturers in Europe are transferring some of their activities, notably watch and strap plating production, out of Europe to cheaper labour areas. Also, the development of inexpensive quartz watches has partly changed the concept of the watch from that of a durable item, to that of a cheap disposable product. Thus, quality decorative finishes are being replaced, in some cases, by thinner plated gold coatings or alternative materials. However, it isfelt that the overall movement towards using gold more sparingly, within the limits of quality maintenance, is approaching a natural limit, and the quantity of gold used as coatings is likely to stabilize in the costume jewellery and watch markets at about 10 to 11 tons per year in Europe over the next five years.

In the U.S.A., about 1 ton of gold is used for plating watch cases and straps. The general outlook for the gold plating industry is optimistic, although the quantities involved are relatively small.

Sales of high quality pens and lighters are expected to remain buoyant in Europe, whereas in the U.S.A. the market for these products tended to decline in 1980. The largest amount of gold used for this type of application was in France, with just over 2 tons. Gold electrodeposits account for the major share of this segment, followed by high carat gold alloys mainly in the form of strips for pen nibs. In the U.S.A., gold is being replaced by base metals in these applications, and where gold-filled material continues to be used, the gold content is being reduced.

The market for opthalmic frames is very sensitive to fashion trends. In the early 1970's the use of gold in spectacle frames went through a minor boom, but over the last few years this has declined. About 1.5 tons of gold was used in 1980 for this purpose in Europe, West Germany being the largest consumer. In this application 70 percent of the gold is consumed in electroplated form, with the remainder being rolled gold. In the U.S.A., where the trend is away from rolled gold towards the thin electroplate, and where large scale import of frames from Japan and Europe has occurred, total consumption of gold in this application is declining and future prospectsfor this market are notvery encouraging. However, there may be periodic revivals in fashion which will have a favourable effect on the use of gold in spectacle frames.

Over the centuries, decorative applications of gold leaf or liquid gold have provided the most visible evidence of the metal in industry and art. Examples of these applications are on china, tableware and bookbiding and decoration. These continue, of course, but on a much smaller scale. Here again, fashion plays an important role, and there has been a demand for rustic earthen tableware in recent years which has had a negative effect on gold consumption in this application.

In Europe, the major application of liquid gold is in chinaware, whereas in the U.S.A., gold is mainly used for decorating glassware. The price of gold is not usually a very significantfactor in the cost of high quality items, for instance, in the U.S.A., the value of the gold on a china plate is approximately U.S. $\$ 0.5$ to 1 , whereas a set of 4 good quality plates might sell for about U.S.\$50. Nevertheless, manufacturers are conscious of increases in the gold price, and gold usage over recent years has tended to decline. In contrast to the state of affairs in electroplating, it is not possible to reduce the usage of liquid goid by reducing thickness or by applying alternatives.

Gold leaf has very good weather resistance properties in exterior applications, however renewed interest in its use has been negated by the high gold price. Consumption of gold in this form is still relatively minot.

Gold is also used in decorating items such as bathroom fixtures, furniture and tableware. The quantity used is relatively small, but there does seem to be some opportunity for growth in these fields.

\section{Future Prospects}

The costume jewellery sector is the one with the greatest potential to influence future trends. Other sectors are toosmall to affect future gold usage to the same degree.

Increased use of gold electroplate in jewellery as well as in other end uses will continue while rolled gold is not expected to make significant gains. Gold consumption in carat jewellery appears to be little affected by this incursion of gold electroplated products. The difference in the prices of the two types of jewellery is so great that they satisfy two

\section{Table V}

Comparison of Consumption of Gold in the U.S.A. in Filled and Plated Decorative Uses. After (3)

\begin{tabular}{c|c|c}
\hline Year & $\begin{array}{c}\text { Gold filled, } \\
t\end{array}$ & $\begin{array}{c}\text { Gold plated, } \\
t\end{array}$ \\
\hline 1977 & 13.6 & $1.6^{*}$ \\
1978 & 14.2 & $1.8^{*}$ \\
1979 & 13.9 & $1.8^{\star}$ \\
1980 & 10.0 & 4.0 \\
-Should be about 1.5 thigher due to methodology \\
inconsistencles.
\end{tabular}


Table VI

Semi-Product Usage of Gold in Western Europe and the U.S.A. in 1980. Estimaled from $(2,4)$

\begin{tabular}{l|r|r|r|r}
\hline \multicolumn{1}{c|}{ Semi-product } & \multicolumn{2}{c|}{ W. Europe, } & \multicolumn{2}{c}{ U.S.A., } \\
& $t$ & $\%$ & $t$ & $\%$ \\
\hline $\begin{array}{l}\text { Electroplating salts } \\
\text { Metallurgical products }\end{array}$ & 28.2 & 66.5 & 39 & 59 \\
$\quad$ (wire, leaf, etc.) & 6.3 & 14.9 & 3 & 4.6 \\
Thick film pastes/ & & & & \\
liquid golds/ & & & & \\
$\quad$ chemicals & 1.9 & 4.5 & 6 & 9 \\
Brazing alloys & 2.0 & 4.7 & 5 & 7.7 \\
Rolled gold & 4.0 & 9.4 & 13 & 19.7 \\
Total & 42.4 & 100.0 & 66 & 100.0
\end{tabular}

distinct types of consumer demand. Within the costume jewellery segment growth prospects for consumption of gold appear to be favourable.

\section{Semi-Product Usage}

Although some reference has been made above to the various forms of semi-product in which gold is supplied and used, the subject is worthy of brief discussion and analysis here: From Table VI, it can be clearly seen that, excluding carat jewellery and dental alloys, approximately two-thirds of the gold consumed in industrial uses in the U.S.A. and Western Europe is in the form of electroplating salts, of which the most widely used is potassium gold(I) cyanide. Rolled gold occupies second place in the U.S.A., reflecting its traditional popularity in that country, although there are indications that consumption of this semi-product may decline in the coming years partly because of its inability to accommodate intricate designs which are beginning to find favour. In Western Europe, the lower consumption figure for rolled gold is clearly demonstrated.

\section{References}

1. 'Gold 1981' Consolidated Gold Fields Ltd , London, 1981

2. C. Michalopoulos, 'U.S. Gold Use in Industrial Applications', Michalopoulos and Parker, Washington, D.C., May, 1981, confidential report to International Gold Corporation Ltd.

3. C. Michalopoulos, 'U.S. Gold Use in Decorative Applications', Michalpoulos and Parker, Washington, D.C., June, 1981, confidential report to International Gold Corporation Ltd.

4. C.G. Wedgewood, 'The Market and Applications in Western Europe for Gold and it Terivatives in the Electrical and Electronic Industries', C.G. Wedgewood and Co., London, July, 1981, confidential report to International Gold Corporation Ltd.

5. 'Decorative and Other Industrial Uses of Gold in Western Europe', Battelle, Geneva, June, 1981, confidential report to International Gold Corporation Ltd

6. 'Spotlight on Connectors', supplement to Electronic News, 1981, November 9.

\section{Anodic Oxide Growth on Gold}

The bulk of the important work on the electrochemical oxidation of gold published up to 1980 has been reviewed by M.J. Nicol (Gold Bull., 1980,13, (2), 46-55 and (3), 105-111). In discussing the thermodynamic predictions and interpretations of the Pourbaix potential/pH diagram for gold, Nicol pointed out that $\mathrm{Au}_{2} \mathrm{O}_{3}$, the most stable trivalent gold oxide, should have a wide region of stability, whereas none exists for either $\mathrm{Au}(\mathrm{I})$ or $\mathrm{Au}(\mathrm{II})$ oxides.

Although the early work on the electrochemical oxidation of gold (before the last decade) was characterized by a lack of sensitivity and resolution inherent in the galvano-static methods in use at the time, a number of features relating to anodic oxide growth on gold were recognized and these have been, in part, confirmed by more recent research using cyclic voltammetry and other sophisticated techniques. The generally accepted conclusion was that, in noncomplexing acid solutions, with increasing electrode potential, chemisorption of oxygen occurs followed by monolayer coverage and finally growth of a bulk oxide layer of composition corresponding closely to that of $\mathrm{Au}_{2} \mathrm{O}_{3}$. In alkaline solutions the final oxide layer was thought to consist of $\mathrm{Au}(\mathrm{OH})_{3}$.

Later and more refined work has shown that the process is more complex than previously thought. A.J. Arvia et al. (J. Electroanal. Chem., 1975, 59, 239) considered that in non-complexing acids, initial formation of an adsorbed $\mathrm{AuOH}$ species is followed either by further oxidation to a higher 'oxide' or by chemical disproportionation to a more stable surface oxide, the stoichiometry of which approximates closely to $\mathrm{Au}_{2} \mathrm{O}_{3}$.

In a recent paper L.D. Burke and M. McRann (J. Electroanal. Chem., 1981, 125, 387-399) report on the electrochemical oxidation of gold in non-complexing alkaline solutions at potentials which are sufficiently high to cause oxide films to form on the gold surface. Thick films (of the order of 100 monolayer equivalents at $2.3 \mathrm{~V}$ ) formed under steady-state polarization conditions and, like those formed in acid solutions, were duplex in character. The layer consisted of a compact, largely anhydrous, inner film at the metal surface, and a much thicker, porous, highly hydrated outer film at the oxide/solution interface. The growth of oxide under alkaline conditions is slower than that in acid medium and reaches a limiting value. The outer film is reduced less easily and oxygen evolution is inhibited in the thick film region at about $2.35 \mathrm{~V}$. Changes in oxygen coordination of cations in the outer region of the compact layer under conditions of thick film growth are assumed by Burke and McRann to enhance the conversion of material in the outer region of this layer to the more highly hydrated form.

Interestingly, these authors discuss possible similarities between the thick oxide films which have been grown anodically on other transition metals of practical significance and the hydrous oxide layer formed on gold. It is intriguing to speculate on the possibility of the current research on anodic polarization of gold electrodes leading to the formation of stable oxide films with interesting electrochromic, charge storage, electrocatalytic, resistive and other properties which could be of industrial significance. 